\title{
High School Student Sustains a Partial Thumb Tip Amputation While Using a Sander in Shop Class - Massachusetts
}

Release Date: March 31, 2017

Investigation: \# 15-MA-1NF-01
Massachusetts Department of Public Health Occupational Health Surveillance Program

\section{SUMMARY}

In 2015 , a $9^{\text {th }}$ grade student enrolled in a Marine Technology program in a Chapter 74 approved public regional technical high school education program sustained a partial thumb tip amputation injury. The student was operating a combination belt and disc sander in shop class when the student's gloved right hand thumb came in contact with the rotating disc sander. The glove and the student's thumb were partially pulled into the machine. Immediately after the incident occurred, a junior who was supervising the freshman student immediately turned off the machine and started to disassemble the machine to free the student. The student was brought to the school nurse who placed a call for emergency medical services (EMS). The local police and EMS arrived at the incident location within minutes. The injured student was transported to a hospital in another state where the partially amputated thumb tip was reattached with 12 stitches and the injured student was then released from the hospital.

Contributing factors identified in this investigation included, greater than $1 / 16$ of an inch space between the sanding table and disc, wearing gloves while operating the sander, not being fully trained on the sander prior to use and inexperience.

The Massachusetts Department of Public Health concluded that to prevent similar occurrences in the future, schools with shop classes should:

- Ensure that students are not wearing gloves when operating machinery with accessible rotating or moving parts;

- Ensure that the space between a disc sander's sanding table and sanding disc is not greater than 1/16 of an inch when being used;

- Ensure students have a clear understanding of the task they will be performing and prohibit any machine operation before being fully trained; and

- Develop comprehensive safety and health plans, as required by Massachusetts regulations, to protect both students and school staff by ensuring that schools are providing conditions that, at a minimum, meet occupational safety and health standards set by the Occupational Safety and Health Administration (OSHA). 


\section{INTRODUCTION}

The Occupational Health Surveillance Program at the Massachusetts Department of Public Health (MDPH) conducted an investigation of this partial thumb tip amputation injury. As part of this process, MDPH together with a representative of the Department of Elementary and Secondary Education (DESE) visited the school site and the incident was discussed with school personnel. MDPH investigated this incident as part of a federally-funded occupational safety and health injury surveillance and prevention program. The goal of the investigation was to determine the contributing factors that led to the injury and to develop recommended countermeasures to prevent future incidents.

\section{SCHOOL}

This Chapter 74 approved public regional vocational technical high school consists of grades nine through 12, has 13 technical programs and has more than 650 students enrolled. Freshman students have the option to explore multiple shops where the students spend one week in three or four shops. The injured student was in the exploratory phase and had just started the exploratory week in the Marine Technology program. The Marine Technology program provides training to students in the recreational marine repair industry, including operation, maintenance, repair, rebuilding and installation of onboard systems. The various skill sets taught include: two and four cycle engine theory, hull maintenance and repair, marine canvas fabrication and repair, gas and diesel engine operation and repair, and welding and precision metal fabrication. The Marine Technology program is designed to provide students with the skills that can eventually lead the student to work in a number of industries and occupations upon graduation, including the United States Coast Guard, and as a marine mechanic, or harbormaster.

\section{SAFETY INFORMATION}

Students are provided some basic instructions during the exploratory phase, but are not provided with the full orientation and training until they have selected a shop. The basic instruction during the exploratory phase is usually provided by either the shop teacher or a student in an upper class. Juniors and freshmen are the two grade levels that are scheduled in the shop at the same time; therefore juniors provide some of the instruction, hands-on training and supervision of the freshmen students.

Once a freshman student selects a technical program, the school provides students with a safety checklist, more in-depth training that includes hands-on training, and then a performance test is administered after the student has spent some time in the shop. The topics covered during the more indepth training included information on acceptable behavior in shop, and rules about appropriate shop attire and personal protective equipment (PPE), such as safety glasses and face shields. The training on the combination belt and disc sander included: the basics of how to turn on and off the machine, how to adjust the two table assemblies, how to disassemble the sander, and how to use the two separate sanding surfaces. The school did have the manufacturer operator's manual for the combination belt and disc sander, but the manual was not part of the training for students.

\section{INJURED STUDENT}

The student was enrolled in the $9^{\text {th }}$ grade, was in the shop exploratory period and had not yet selected a technical program as a concentration. It was the first day of the student's week-long Marine Technology program exploratory session when the incident occurred. Shop class started at 7:40 a.m., went until 2:10 p.m., and the incident occurred around 9:30 a.m. on a Monday. At the time of the incident, the student was wearing the school provided face shield and heavy duty leather gloves. 


\section{INCIDENT LOCATION}

The Marine Technology program shop, in which the incident occurred, is located on the ground floor of the school building. It is a large shop with a large spray booth and multiple work bays with overhead doors to get larger objects, such as boats and trailers, inside the shop area. The equipment available for students to operate while in the Marine Technology shop included both handheld tools and stationary equipment. The shop is equipped with both local and general ventilation systems. The sander is connected to a local ventilation system/dust collector.

\section{EQUIPMENT}

The stationary sander that the student was operating at the time of the incident was a combination belt and disc sander (Figure 1). The sander was purchased new and had been installed in the shop for about one year when the incident occurred. The sander's overall dimensions are 24 inches deep by 31 inches wide by 54 inches high. There is a manufacturer provided power push button switch on the left side of the machine. This type of sander is designed to remove small amounts of material from the workpiece. The operator's manual for the sander states that the operator should not wear gloves while using the sander.

The student was using the disc portion of the machine when the incident occurred. The sanding disc on the machine is an abrasive 12 inch diameter disc. The disc rotates counterclockwise at 2,375 revolutions per minute. The machine's sanding work table for the sanding disc is 17 inches long by nine inches deep. The operator's manual states that the sanding disc table can be adjusted to be on an angle from 15 degrees upwards to 45 degrees downwards. The inside edge of the adjustable sanding table should always be within $1 / 16$ of an inch or less of the sanding disc. The workpiece being sanded should only come in contact with the left side of the sanding disc (downward side) and should be held against the sanding table at all times.

\section{INVESTIGATION}

The day of the incident was the student's first day of a weeklong exploratory phase in the Marine Technology program and there were three shop instructors present. At the time of the incident, the student was being supervised primarily by an older classmate, a junior. The junior who was supervising the student that was injured was also supervising two other freshmen that were in their exploratory phases.

The student was making a metal cube out of flat stock metal (Figure 2). The cube was to be made out of six three-by-three inch pieces of metal that were then to be welded together (Figure 2). The student had cut out the six three-by-three inch metal pieces and was going to use the disc sander to smooth all of the edges. The junior showed the student how to use the combination sander and then the junior observed the student sand a metal piece using the disc sander. While wearing a face shield and general heavy duty leather gloves (Figure 2), the student started to sand the other metal pieces while the junior went to assist other freshmen. The sanding disc table was set to the neutral tilt position, zero degrees. No one observed the incident, but it appears that the student was holding a three-by-three inch metal workpiece close to the edge of the workpiece that was being sanded. Then one of the gloves the student was wearing came in contact with the rotating sanding disc, pulling the glove and the student's thumb down between the rotating sanding disc and the sanding table. 
The junior heard a noise and turned to the sander and saw that the student's hand was stuck in the machine. The junior immediately shut off the sander using the power push button switch on the machine and then started to disassemble the sander to remove the sanding work table and freed the student. The glove was kept on the student's hand and the student was brought to the school nurse's office. The school nurse called for emergency medical services (EMS) and also notified the student's emergency contact. EMS arrived within minutes and the student was transported to a hospital in a neighboring state. The partially amputated thumb tip was reattached with 12 stitches and the student was released from the hospital. The junior who removed the sanding table to free the injured student indicated that it was possible that the inside edge of the sanding table might have been adjusted more than $1 / 16$ of an inch from the sanding disc at the time of the incident.

\section{CONTRIBUTING FACTORS}

Injuries are often the result of one or more contributing factors or key events in a larger sequence of events that ultimately result in the injury. The Massachusetts Department of Public Health identified the following contributing factors in this incident.

- wearing gloves while operating machinery

- not being fully trained prior to machine use

- inexperience

In addition, if the space between the sanding table and the sanding disc truly was greater than 1/16 of an inch at the time of the incident, then this would also be a contributing factor in this incident.

\section{RECOMMENDATIONS/DISCUSSION}

\section{Recommendation \#1: Schools with shop classes should ensure that students are not wearing gloves when operating machinery with accessible rotating or moving parts.}

Discussion: Gloves should not be worn when operating machinery with accessible rotating or moving parts. This also includes some machinery that might be guarded, because not all guards can completely protect the operator from the point of operation where there could be moving and rotating parts. This warning to not wear gloves while operating certain machines includes the operation of stationary belt and disc sanders.

In this incident, the student was operating the sander while wearing gloves. It was suggested during the investigation that the gloves were being worn because the metal piece being sanded might get hot. In the "Warnings" section located in the beginning of the manufacturer's operating manual for the sander, it states that before operating the sander, the operator should remove ties and jewelry, not wear loose clothing, roll up sleeves to the elbow, and to confine long hair. The manual also state; "Do not wear gloves."

In addition, the "Operation" section of the manual contains a warning that states: "Caution. Keep in mind that abrasive sanding develops heat, so burns can occur on wood if you try to remove material too fast. With metal, it may be necessary to have a container of water nearby to keep the workpiece cool enough to hold it by hand." The school did have a copy of this manual that was kept in the shop office. An operating manual written by manufacturers' contain important information on how the manufacturer intended the equipment to be operated. 


\section{Recommendation \#2: Schools with shop classes should ensure that the space between a disc sander's sanding table and sanding disc is not greater than 1/16 of an inch when being used.}

Discussion: It was mentioned during the site visit that the space between the sanding table and the sanding disc might have been greater than 1/16 of an inch. When this space is too large, the risk of the work piece, body part, or clothing becoming caught between the sanding table and the rotating sanding disc increases. In this incident, if the sanding table was positioned more than $1 / 16$ of an inch from the sanding disc, this gap would more easily allow a gloved hand that came in contact with the rotating sanding disc to get pulled down between the sanding table and sanding disc.

To avoid having a work piece or fingers caught between the sanding table and the rotating sanding disc, the sanding table edge should be positioned at a maximum of 1/16 of an inch away from the sanding disc. If this space is greater than $1 / 16$ of an inch, then the sanding table should be adjusted immediately. To ensure that this space is not too large, before using the disc sander, the sanding table position should be checked and adjusted when needed.

\section{Recommendation \#3: Schools with shop classes should ensure students have a clear understanding of the task they will be performing and prohibit any machine operation before being fully trained.}

Discussion: In this incident, the injured student was in the weeklong shop exploratory stage and had not gone through the entire training for the sander at the time it was being operated. Briefly explaining a procedure may not ensure that individuals, including teenagers and less experienced adults, fully comprehend the tasks at hand or feel comfortable enough to safely perform the task. Teenagers typically have limited experience with machinery found in shops and this, combined with a desire to demonstrate independence, may lead to hesitation in speaking up about their concerns, including asking for a process to be re-explained to them.

Students should never be allowed to operate any machinery prior to being fully trained on that specific machine. Therefore, if students are not provided full training on machinery during the weeklong exploratory session and will only receive the full training until they are officially enrolled in a shop, then these students should not be allowed to operate the machinery during the exploratory session. Furthermore, when trained upper class students are the individuals providing the instruction to new and less experienced students, ideally the ratio of instructor to student would not exceed one to one. This would help ensure the upper class students are not given more responsibility than they can handle.

A process must be developed to help keep students safe while completing shop tasks, including during machine operation. This process should be part of a comprehensive safety and health plan as required for each chapter 74 state approved vocational program (see recommendation \#4 below) and should outline steps to assess student comprehension, competency, and comfort level of the machine they are going to use. This should include instructors directly asking students exactly how comfortable they feel with operating the machine and asking them to verbally state the proper machine operating procedures to the instructor. Then a written exam on safe operation of the machine should be administrated before the students are allowed to operate the machine.

Based on the results of the assessment and the exam, the instructor can make an informed decision on the level of supervision and/or retraining needed. It is imperative that instructors immediately correct 
and point out to students when any observed unsafe actions are being performed. Some of this evaluation process might have been developed as part of the Vocational Technical Education Framework. Strand 1 (Safety and Health Knowledge and Skills) and Strand 2 (Technical Knowledge and Skills) of this Framework must be followed as a general outline of the safety requirements of each shop.

\section{Recommendation \#4: Schools with vocational shops should develop comprehensive safety and health plans, as required by Massachusetts regulations, to protect both students and school staff by ensuring that schools are providing conditions that, at a minimum, meet occupational safety and health standards set by the Occupational Safety and Health Administration (OSHA).}

Discussion: Chapter 74 approved vocational technical education programs provide students with important opportunities to learn technical skills and to introduce them to various work environments. Occupational safety and health is a crucial component of work preparation, both to ensure safety in the school shop and to develop safe work skills for the future. Schools are required by the Massachusetts Board of Education, under the Code of Massachusetts Regulations (603 CMR 4.03), to provide environments that, at a minimum, meet safety and health standards set by the Occupational Safety and Health Administration (OSHA) and to train students about these standards and about hazard recognition.

The Code of Massachusetts Regulation (603 CMR 4.03(3) (d)) - Vocational Technical Education Location (Facilities) and Equipment, specifically states that: "The school shall develop and implement a comprehensive safety and health plan to safeguard the safety and health of all students and school personnel. The regulations of the Occupational Safety and Health Administration (OSHA) governing work sites shall serve as the minimum standards for safety in the vocational technical education program. The plan should include provisions for safety inspections of all facilities, safety training for all students and staff and the use, storage and disposal of toxic and hazardous materials." Each Chapter 74 state approved vocational program must develop a shop specific comprehensive safety and health plan that includes training requirements for each piece of equipment. When developing equipment specific operational trainings, the manufacturer's operating manual will provide valuable information. The OSHA document Recommended Practices for Safety and Health Programs is a useful document to reference when developing or updating a safety and health plan (www.osha.gov/shpguidelines/). (Note: When the same equipment is used in multiple shops, the equipment safety instructions can be shared between shops. However, each student must be trained separately at each shop for each piece of equipment being operated.)

In addition, the Massachusetts Department of Labor Standards (DLS), in accordance with Massachusetts General Law Chapter 149 Section 6, is charged with inspecting public sector workplaces, including public schools, in Massachusetts and determining what procedures and practices are required to protect workers from injury and illness. As a matter of policy, DLS references OSHA Standards, in determining whether proper procedures are being followed to protect workers.

\section{REFERENCES}

American Journal of Industrial Medicine. Protecting Youth at Work, 36:579-582 (1999), Wegman, Davis. 
Code of Massachusetts Regulations. 603 CMR 4.03. Program Approval Criteria, Vocational Technical Education.

General Laws of Massachusetts, Title XXI, Labor and Industries, Chapter 149: Section 6. Safety devices and means to prevent accidents and diseases generally.

NIOSH Alert: Preventing Deaths, Injuries, and Illnesses of Young Workers. DHHS NIOSH Publication No. 03-128.

OSHA. Code of Federal Regulations. 29CFR 1910.213. Woodworking machinery requirements. Washington, DC: U.S. Printing Office, Office of the Federal Register.

OSHA. Code of Federal Regulations. 29 CFR 1926.21. Safety training and education. Washington, DC: U.S. Printing Office, Office of the Federal Register. 
Figure 1 - Combination sander involved in the incident

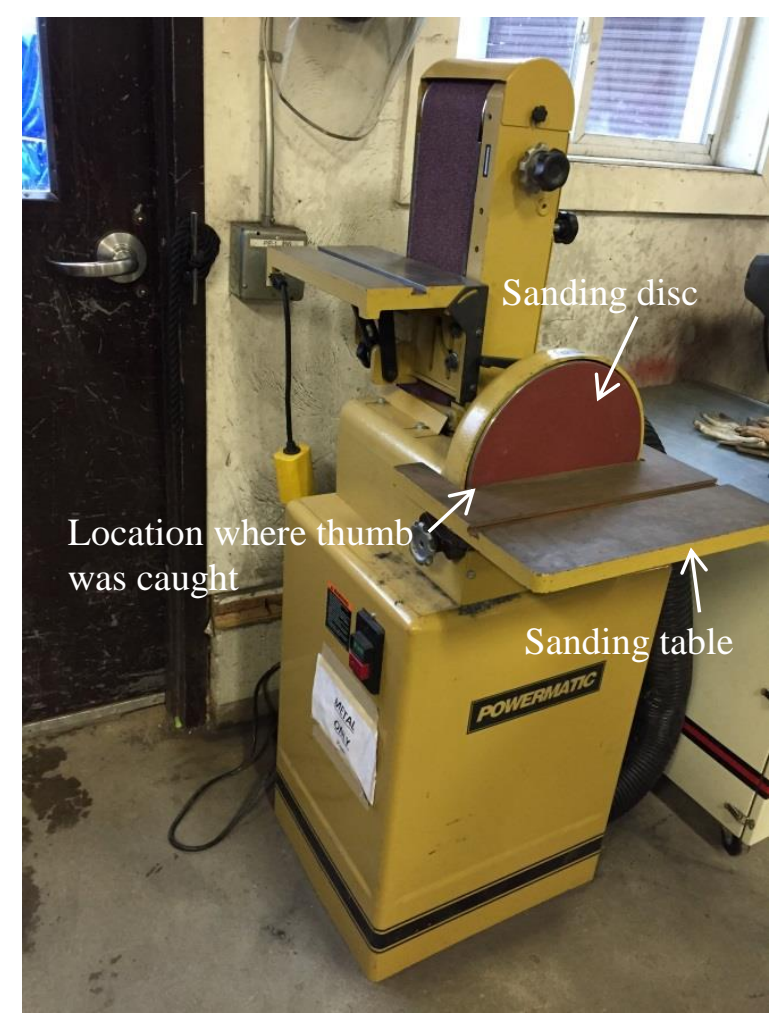

Figure 2 - Similar metal work pieces being sanded and gloves being used

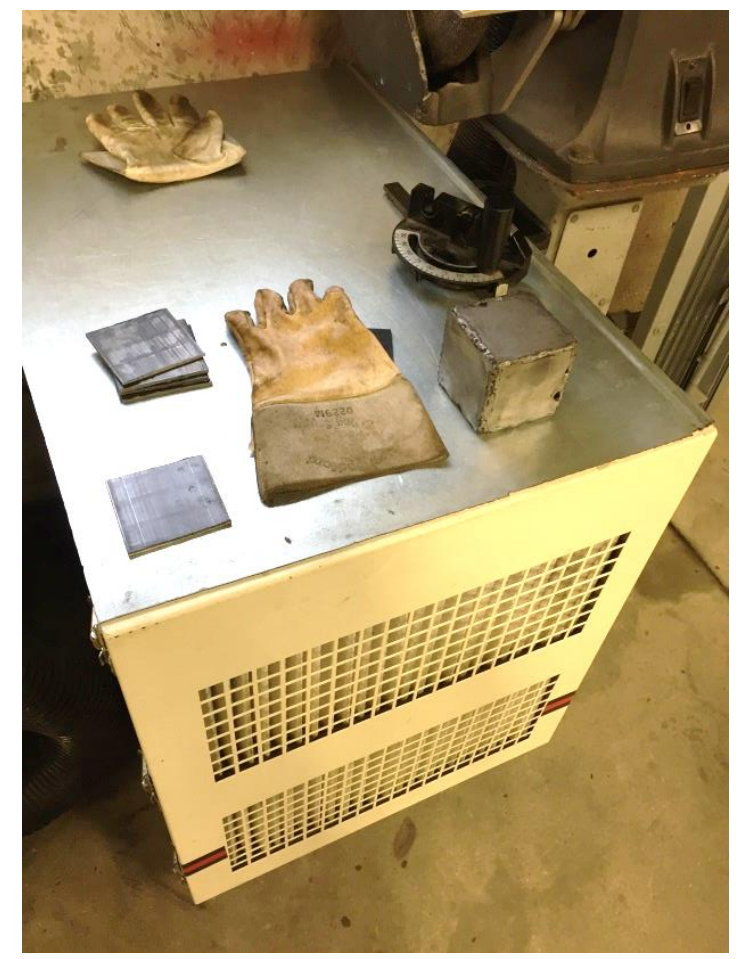

